\title{
Injury-related falls from bicycles, skateboards, roller skates, and non-motorized scooters in the United States: 2005 - 2014
}

\author{
William Milczarski*1, Peter Tuckel ${ }^{2}$, Richard Maisel $^{3}$ \\ ${ }^{1}$ Department of Urban Policy and Planning, Hunter College - City University of New York, New York, NY, United States \\ ${ }^{2}$ Department of Sociology, Hunter College - City University of New York, New York, NY, United States \\ ${ }^{3}$ Department of Sociology, New York University, New York, NY, United States
}

Received: July 18, 2017

DOI: $10.5430 /$ jer.v4n1p16
Accepted: October 12, 2017

Online Published: October 27, 2017

\begin{abstract}
Purpose: To provide an updated and comparative analysis of injury-related falls from bicycles, skateboards, roller skates and non-motorized scooters in the United States.

Methods: The study used two national databases - the Nationwide Emergency Department Sample and the Nationwide Inpatient Sample - and subnational databases for New York, California, and Maryland covering the time span from 2005 to 2014. Univariate and multivariate analyses (negative binomial regression) were performed to identify effects of age, gender, racial-ethnic background, and region on the incidence of injury-related falls from each of the four devices.

Results: The rate of injuries due to falls from bicycles far surpassed the rates due to falls from the other devices. When a measure of "exposure" is taken into consideration, however, the rate of injuries from skateboards outstripped the rates from bicycles or roller skates. The profile of patients who were injured from falls from each of the four devices was distinctive. Asian-Americans were greatly underrepresented among those who suffer a fall-related injury from any of the four devices. The incidence of injuries attributable to falls varied considerably by geographic region.

Conclusion: Public health officials need to be mindful that while certain activities such as scootering might be gaining in popularity, the number of injuries sustained from bicycles still dwarfs the number attributable to falls from skateboards, roller skates, and scooters combined. Thus special attention needs to be paid to both prevent falls from bicycles and specific treatment modalities. It is important for public health officials to gather injury data at the local level to allocate prevention and treatment resources more efficiently.
\end{abstract}

Key Words: Injuries, Falls, Bicycles, Skateboards, Roller skates, Non-motorized scooters, Emergency department

\section{INTRODUCTION}

Falls from non-motorized wheeled devices such as bicycles, skateboards, roller skates, and scooters result in a substantial number of emergency department (ED) visits and inpatient hospital stays in the United States. In 2014 (the most recent year for which nationwide data are available), there were an estimated 439,960 emergency department visits due to a fall from a bicycle, skateboard, roller skates, or scooter. ${ }^{[1]}$ In the same year, there were an estimated 23,880 hospital admissions stemming from falls from one of these wheeled de-

${ }^{*}$ Correspondence: William Milczarski; Email: wmilczar@hunter.cuny.edu; Address: Department of Urban Policy and Planning, 695 Park Avenue, New York, NY 10065, United States. 
vices. ${ }^{[1]}$ Aside from the significant levels of morbidity (and, in rare cases, mortality) caused by these types of falls, emergency department charges totaled a staggering $\$ 946,964,708$ for 2014. ${ }^{[1]}$ Dividing this sum by the total number of ED visits in 2014 yields an average figure of $\$ 2,152$ per visit. The high incidence of falls from these devices and the associated costs constitute a concern which needs to be seriously addressed by public health practitioners.

Numerous studies have examined injury-related falls from these human-powered vehicles. Many of these studies focus on just one human-powered vehicle such as bicycles, ${ }^{[2]}$ skateboards, ${ }^{[3,4]}$ roller skates, ${ }^{[5]}$ or scooters. ${ }^{[6-8]}$ Each of these studies enhances our understanding of the injury risks associated with a particular type of vehicle but inherently precludes direct comparisons across types of vehicles, particularly since the analyses generally rest on different databases, encompass different time frames, and/or cover different geographic locations. Thus, it is difficult to assess the relative risks of injuries incurred by falling off a specific type of vehicle. The literature also consists of a few studies which examine injury-related falls from more than one of these devices. ${ }^{[9-13]}$ While these studies permit comparisons across different kinds of vehicles, they are often limited in their scope by focusing on a specific type of injury (e.g., head injuries), cover a narrow time frame, or do not pertain to the United States.

The present study aimed to provide an updated, comprehensive analysis of injuries from falls from bicycles, skateboards, roller skates (including in-line skates), and non-motorized scooters eventuating in a visit to a hospital either as an outpatient or inpatient. The analysis examines injury-related falls from these human-powered vehicles over several years and is based on both national and state-level databases.

The current study had four main objectives: 1) to gauge the overall incidence of injuries from falls from bicycles, skateboards, roller skates, and scooters over time, 2) to construct a demographic profile of patients who suffer an injury from each of these non-motorized devices, 3 ) to assess the relative risk of injury of different demographic subgroups in the US population by product type, and 4) to identify the types of injuries most frequently incurred in falls from each of the four product types.

\section{MATERIALS AND METHODS}

The analysis for this study rests upon emergency department visits and hospital admissions at both the national and subnational levels. National level data were obtained from two sources: the NEDS (Nationwide Emergency Department Sample) ${ }^{[14]}$ and the NIS (Nationwide Inpatient Sample). ${ }^{[15]}$
Both of these databases are created each year by the Healthcare Cost and Utilization Project (HCUP) which is under the auspices of the Agency for Healthcare Research and Quality (AHRQ). The NEDS database rests upon roughly 30 million hospital-based ED visits and the NIS database rests upon more than 7 million inpatient admissions. HCUP generates national estimates for ED visits and hospital stays, respectively, from these two databases. Both the NEDS and NIS databases include information about basic demographic characteristics of patients, diagnoses, treatments, and hospital charges. The present study utilized the NEDS and NIS databases for the years 2006, 2009, 2012, and 2014.

In addition to these national databases, this study examined patient-level hospital records from New York, California, and Maryland. Similar to the NEDS and NIS data sets, these state-level patient records consist of a broad array of diagnostic and treatment variables, but they also contain information concerning the racial-ethnic background of patients as well as geographic-based attributes of patients such as their zip code or county.

The data for New York came from the SPARCS (Statewide Planning and Research Cooperative System) which is under the auspices of the New York State Department of Health. ${ }^{[16]}$ SPARCS gathers data for every inpatient, outpatient, and ambulatory surgery patient treated in a hospital in New York State. For the purposes of this analysis, a subset of the SPARCS data covering patients who reside in New York City was created to compare New York City residents with other inhabitants in New York State. The SPARCS data for both New York State and New York City in this study span the years from 2005 to 2014 .

The data for California were obtained from the OSHPD (Office of Statewide Health Planning and Development) and consisted of inpatient, emergency department, and ambulatory surgery records for patients from all hospitals in the state. ${ }^{[17]}$ A subset of these data was extracted from individuals living in Los Angeles County so as to undertake a comparative analysis of Los Angeles County patients versus those from the rest of the state. The California and Los Angeles County data sets cover the years from 2009 to 2014 .

The sources for the Maryland data were three HCUPgenerated databases: the SEDD (State Emergency Department Database) the SID (State Inpatient Database) and the SASD (State Ambulatory Surgery and Services Database) for Maryland. ${ }^{[18]}$ From these three databases, a subset of data was extracted for Baltimore city to draw comparisons between the city of Baltimore and other residents of the state of Maryland. The time period covered for both Maryland and the city of Baltimore was from 2009 and 2014. 
Each of the data sets employed in this study include ICD-9 External Cause of Injury codes (E-codes) for injury-related falls. The E-codes are as follows: E826.1 (fall from bicycle), E885.0 (fall from a non-motorized scooter), E885.1 (fall from roller skates/in-line skates), and E885.2 (fall from skateboard). These E-codes served as the dependent variables in the study's analyses.

The demographic correlates of patients who sustained an injury from a fall varied by data set. Both the national and state-level data sets included the patient's age and gender. The HCUP databases used in this analysis (NEDS, NIS, Maryland, and Baltimore city) also included a measure of a patient's socioeconomic status which was based on a quartile classification of the median household income of a patient's zip code. In addition, the HCUP databases included a measure of a patient's location on a 6 point urban-rural scale ranging from a value of 1 ("central counties of metro areas of $\geq 1$ million population") to a value of 6 ("not metropolitan or micropolitan counties"). A key feature of the sub-national data bases (New York State, New York City, California, Los Angeles County, Maryland, Baltimore city) was the inclusion of two variables denoting a patient's race and ethnicity. From these two variables, a typology of a patient's racialethnic background was constructed: non-Hispanic white, non-Hispanic black, non-Hispanic Asian, and Hispanic.

All of the databases examined in this study included a clinical classification of diagnoses (developed by AHRQ) which divides up the universe of diagnoses into a more parsimonious set of categories. The databases also included information concerning the month a patient visited an ED or was admitted to a hospital. Finally, information regarding charges were collected in each database, excluding the California and Los Angeles county data sets.

The information contained in each data set was "deidentified". That is to say, personal information was masked to protect the anonymity of every patient.

To measure the overall trends in injuries by type of nonmotorized vehicle for both inpatients and outpatients, yearly rates were constructed by dividing national estimates of the incidence of injuries by total US population multiplied by 100,000 . A similar calculation was made to compare the injury rates of the four non-motorized vehicles by geographic region for the year 2014.

Univariate analyses were performed on the data to describe the demographic characteristics of individuals who visited an emergency department due to falls from one of the four devices and also to describe the types of injuries sustained in such falls among both outpatients and inpatients.
To measure the simultaneous effect of year, geographic location, and demographic variables (i.e., age, gender, and racial-ethnic background) on the injuries caused by falls from bicycles, skateboards, roller skates, and scooters, a series of four negative binomial regression analyses were performed. Negative binomial regression analyses were employed instead of Poisson regression analyses because of marked overdispersion in the data sets. In each analysis population-based counts of outpatients and inpatients combined who were injured due to a fall from one of the four wheeled devices served as the dependent variable. The same set of predictor variables was employed in each analysis. Year was an interval-level variable with values ranging from 1 (2005) to 10 (2014). Geographic location consisted of a set of 5 dummy-coded variables representing New York State, New York City, California, Los Angeles County, and Maryland with the city of Baltimore serving as the reference category. Gender was coded as a dichotomous variable with female being the reference category. Age consisted of a set of 5 dummy-coded variables representing the following ranges: 1) under 5 years of age, 2) 5 to 9 years of age, 3) 10 to 14 years of age, 4) 15 to 24 years of age, and 5) 25 to 44 years of age. The reference category was composed of patients who were 45 years and older. Finally, race-ethnicity was coded as a set of three dummy variables representing non-Hispanic whites, non-Hispanic blacks, and non-Hispanic Asians with Hispanics serving as the reference category.

To account for varying levels of risk of injury from falls associated with different populations, an offset variable was introduced into each of the regression equations. The offset variable was constructed in a two-step process. First, contemporaneous census figures were derived to tally the population of individuals in each year within each geographic location belonging to each gender, age, and racial-ethnic group. So, for example, one population total would consist of female, non-Hispanic Asians between the ages of 15 to 24 who resided in New York State in 2007. Altogether, 2,064 population totals were calculated by partitioning year, geographic location, gender, age, and racial-ethnic group into all possible segments. Next, these 2,064 population totals were transformed by taking their natural log.

A typology of injuries caused by falls from the each of the four non-motorized vehicles was created. The Clinical Classification Software (CCS) for ICD-9 (developed by AHRQ) was used to classify the types of injuries.

\section{RESULTS}

\subsection{Overall trends}

The data in Figure 1, culled from the NEDS database, depicts the nationwide rates of fall-related injuries from bicycles, 
skateboards, roller skates, and scooters during the time interval from 2006 to 2014. The data show that the incidence of injuries caused by falling from a bicycle greatly surpasses the incidence of injuries due to falling from the three other wheeled devices for each year under investigation. With the exception of scooters in which the injury rate trends upwards, the data also show a decrease in injury rates between the end-point years of 2006 and 2014 for bicycles, skateboards, and roller skates. In the case of bicycles and skateboards, though, this decrease was not monotonic but first spiraled upwards before undergoing a decline. The swing upwards in the injury rate for scooters represented a continuation of a long-term trend spanning the years from 1990 to $2011 .^{[8]}$

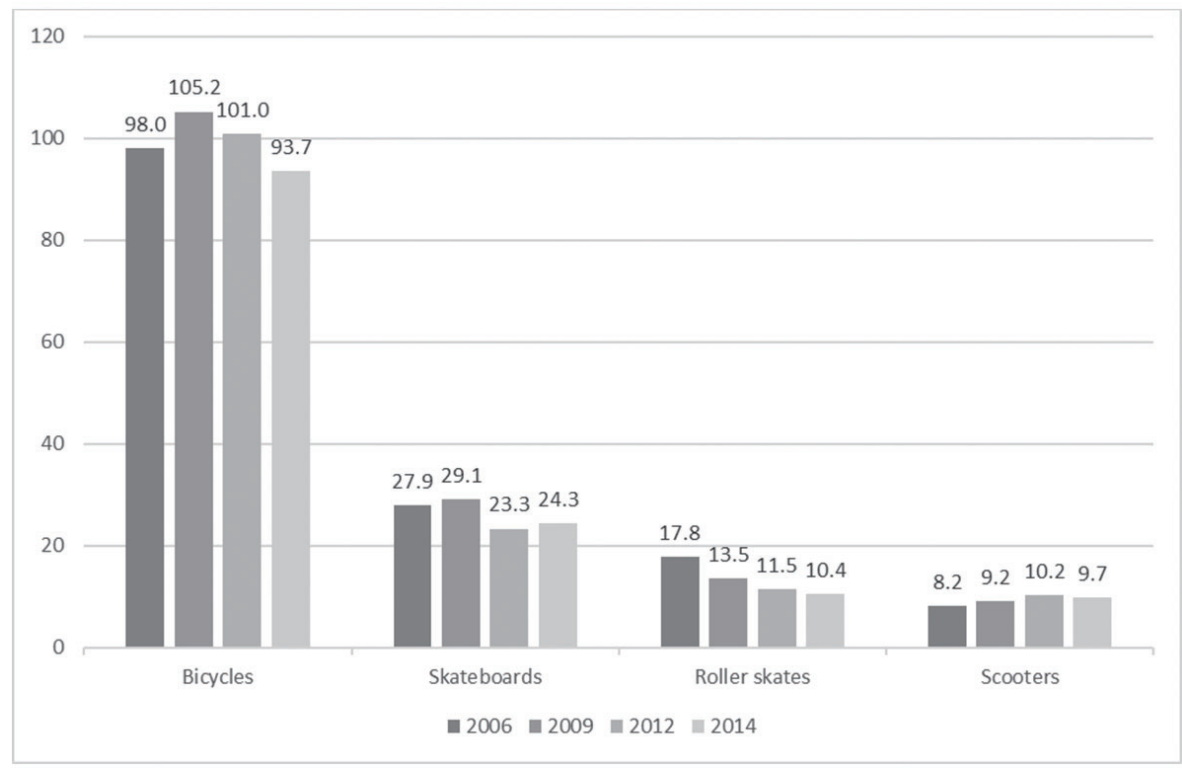

Figure 1. Trends in Injury Rates per 100,000 Population by Type of Non-motorized Vehicle (Source: Nationwide Emergency Department Sample)

The ranking of the nationwide injury rates by product type for inpatients during this same time span closely mirrored that for outpatients (see Figure 2). Again, the rate for bicycle injuries far outstripped the corresponding rates for skate- boards, roller skates, and scooters. With respect to trends over time, the bicycle injury rate generally inclined upwards, the rates for skateboards and roller skates decreased, and the change in rate for scooters was negligible.

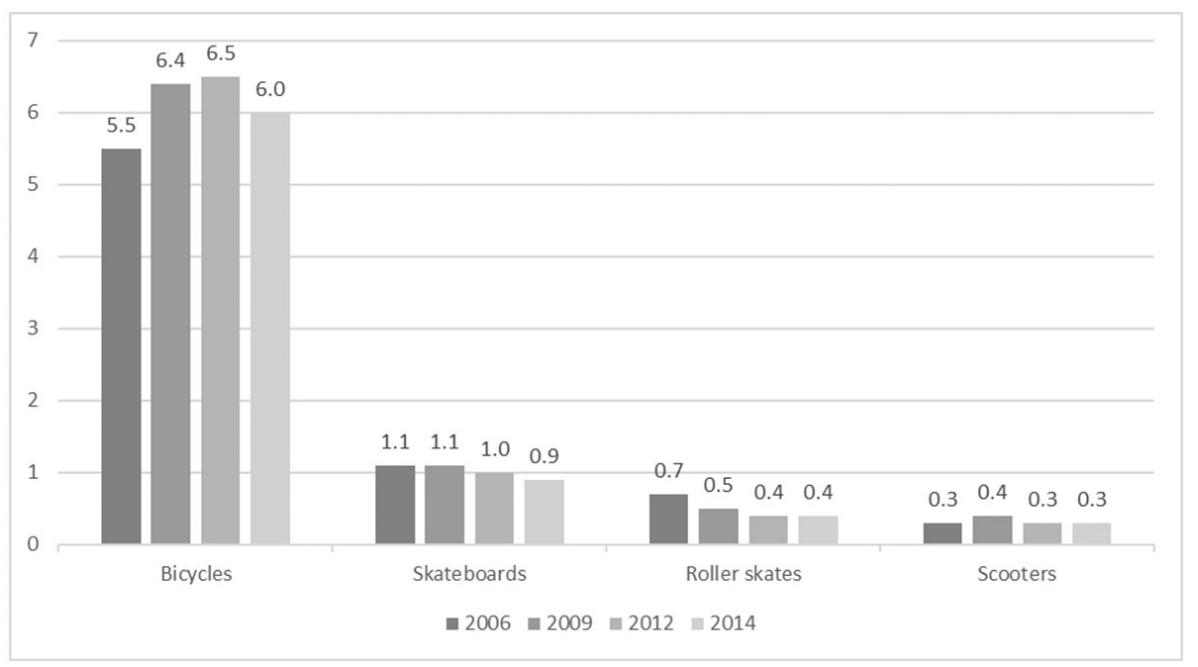

Figure 2. Trends in Injury Rates per 100,000 Population by Type of Non-motorized Vehicle (Source: Nationwide Inpatient Sample) 
The trends presented in Figures 1 and 2 are based on injury rates per 100,000 inhabitants in the U.S. population. A more precise measure of injury rates would be based on the number of individuals who actually participate in bicycle riding, skateboarding, roller skating, and scootering rather than the number of individuals in the general population. Unfortunately, data pertaining to participation in these activities is sparse with respect to the particular activity, extent of participation in the activity, time period covered, and geographic scope. One data set which does exist estimates overall participation in three of these activities (bicycling, skateboarding, and roller skating) for the years 2010, 2012 and 2014. These data are based on on-line panels maintained to be representative samples of the U.S. population. ${ }^{[19-22]}$ Using these estimates rather than population totals in the denominator, the injury rates (both outpatients and inpatients combined) for bicyclists were 888.63 for $2010,810.27$ for
2012, and 754.72 for 2014. The comparable injury rates for skateboarders for the three years were 1250.25, 1225.26, and 1220.63, respectively, and for roller skaters are 592.57, 562.36, and 565.42, respectively. These data revealed that when estimated participation in the use of these devices ("exposure") was taken into consideration, the injury rate for skateboarders outpaced that of bicyclists.

The national data obscured regional variations in both the magnitude and direction of the injury rates within each product category (see Figure 3). One example of the regional variation was the injury rates for bicycles in 2014. In California, omitting Los Angeles County, the rate was 130.0; in New York State excluding New York City, the rate was 98.7; and in Maryland, excluding Baltimore city, the rate was just 66.8. Wide disparities also exist between cities. For instance, the rate for bicycles in Baltimore city was 105.7 and for New York City was 75.4.

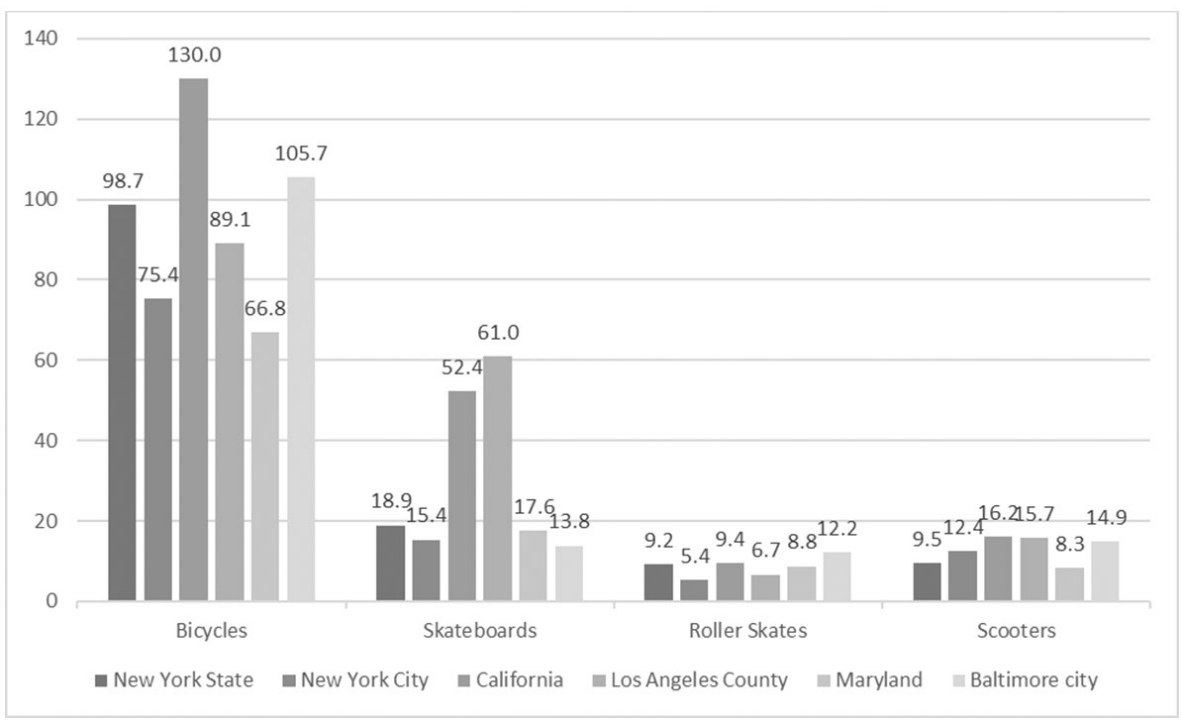

Figure 3. Comparison of 2014 Injury Rates per 100,000 Population of Non-motorized Vehicles by Geographic Region

The geographic variation in injury rates extended as well to the other types of wheeled vehicles besides bicycles. To illustrate with one other example: in Los Angeles County, the injury rate from skateboards in 2014 was 61.0 and in California, the figure stood at 52.4. By comparison, the injury rate from skateboards in 2014 in New York was just 18.9 and the corresponding rate in New York City was a mere 15.4.

The trend lines for skateboards also varied by region. In New York, Maryland, and Baltimore city, the injury rates for skateboards decreased while in both California and Los Angeles County they climbed upwards over time. This geographic variation in the size and direction of injury rates for the different wheeled vehicles suggest that caution must be exercised in assuming that the national injury rates discussed above are applicable to specific localities.

\subsection{Demographics}

Table 1, based on the NEDS data set, displays the demographic characteristics of patients visiting an ED due to falls from each of the four non-motorized devices. The data show that patients who fall from bicycles, skateboards, roller skates, and scooters each possesses a distinctive profile. In terms of age, the distribution of patients who fell from a bicycle tended to skew toward the higher age brackets. Fully one-fifth $(21 \%)$ of these individuals were between 25 and 44 years of age, and an additional one-quarter (25.5\%) were 45 years of age and older. With the exception of children under 
5 , cyclists were also moderately represented in each of the remaining age categories. The moderate or heavy representation of cyclists in almost every age category is an indicator of the popularity of cycling across the entire age spectrum and helps to explain why injury-related falls from bicycles far exceed the injuries sustained from falls from the other wheeled devices.

Table 1. Demographic Characteristics of Individuals Who Visit an Emergency Department Due to Falls from Bicycles, Skateboards, Roller skates, and Non-motorized Scooters: 2014

\begin{tabular}{|c|c|c|c|c|}
\hline & Bicycles & Skateboards & Roller skates & Scooters \\
\hline \multicolumn{5}{|l|}{ Age } \\
\hline Under 5 & $4.2 \%$ & $0.9 \%$ & $1.0 \%$ & $10.7 \%$ \\
\hline 5 to 9 & $15.9 \%$ & $7.2 \%$ & $18.4 \%$ & $41.8 \%$ \\
\hline 10 to 14 & $17.0 \%$ & $29.7 \%$ & $33.3 \%$ & $29.2 \%$ \\
\hline 15 to 24 & $16.4 \%$ & $47.2 \%$ & $14.1 \%$ & $6.2 \%$ \\
\hline 25 to 44 & $21.0 \%$ & $12.9 \%$ & $20.9 \%$ & $6.2 \%$ \\
\hline 45 and over & $\underline{25.5 \%}$ & $\underline{2.0 \%}$ & $\underline{12.3 \%}$ & $\underline{5.9 \%}$ \\
\hline & $(100 \%)$ & $(100 \%)$ & $(100 \%)$ & $(100 \%)$ \\
\hline Total number & 298,314 & 77,566 & 33,149 & 30,870 \\
\hline \multicolumn{5}{|l|}{ Gender } \\
\hline Male & $72.6 \%$ & $80.4 \%$ & $33.9 \%$ & $59.1 \%$ \\
\hline Female & $\frac{27.4 \%}{(100 \%)}$ & $\frac{19.6 \%}{(100 \%)}$ & $\frac{66.1 \%}{(100 \%)}$ & $\frac{40.9 \%}{(100 \%)}$ \\
\hline Total number & 298,298 & 77,567 & 33,149 & 30,871 \\
\hline \multicolumn{5}{|l|}{$\begin{array}{l}\text { Median household income: national quartile } \\
\text { for patient zip code }\end{array}$} \\
\hline $1^{\text {st }}$ quartile & $27.3 \%$ & $23.1 \%$ & $29.2 \%$ & $25.9 \%$ \\
\hline Total number & 290,487 & 76,232 & 32,692 & 30,492 \\
\hline $\begin{array}{l}\text { Central counties of metro areas of } \geq \text { one million } \\
\text { population } \\
\text { Total number }\end{array}$ & $\begin{array}{l}29.1 \% \\
294,700\end{array}$ & $\begin{array}{l}35.6 \% \\
77,126\end{array}$ & $\begin{array}{l}23.9 \% \\
33,043\end{array}$ & $\begin{array}{l}36.6 \% \\
30,796\end{array}$ \\
\hline \multicolumn{5}{|l|}{ Admission month } \\
\hline January to March & $11.9 \%$ & $16.7 \%$ & $29.8 \%$ & $16.9 \%$ \\
\hline April to June & $34.3 \%$ & $31.4 \%$ & $26.9 \%$ & $37.0 \%$ \\
\hline July to September & $39.5 \%$ & $33.2 \%$ & $22.5 \%$ & $31.9 \%$ \\
\hline October to December & $\frac{14.3 \%}{(100 \%)}$ & $\frac{18.7 \%}{(100 \%)}$ & $\frac{20.8 \%}{(100 \%)}$ & $\frac{14.1 \%}{(100 \%)}$ \\
\hline Total number & 254,230 & 66,762 & 28,141 & 27,313 \\
\hline
\end{tabular}

Source: 2014 Nationwide Emergency Department Sample (NEDS). Data based on the following ICD-9 codes: E826.1 (fall from bicycle), E885.0 (fall from non-motorized scooter), E885.1 (fall from roller skates) and E885.2 (fall from skateboard).

A strikingly different age distribution from patients who fell from a bicycle is found for patients who fell from a skateboard. Nearly half $(47.2 \%)$ were between the ages of 15 and 24 and almost a third (29.7\%) were between 10 and 14 years of age. Patients who fell from a non-motorized scooter also tended to be clustered in specific age groups. Approximately two-fifths $(41.8 \%)$ were found in the 5 to 9 age category and about a third (29.2\%) were found in the 10 to 14 age category. By comparison, roller skaters tended to be more evenly distributed across all age groups, excepting children under 5.

With respect to gender, males tended to predominate among patients who fell from bicycles, skateboards, and scooters with females predominating among patients who fell from roller skates. The gender divide was most glaring among skateboarders with males constituting 80.4 percent of the patients. A similarly skewed distribution favoring males (89\%) was uncovered by McKenzie et al. (2016) who examined data from the National Electronic Injury Surveillance System (NEISS) during the time interval from 1990 to 2008. ${ }^{[3]}$ The gender imbalance was also pronounced among cyclists with males comprising $72.6 \%$ of the patients.

Socioeconomic status, as measured by the median household income of a patient's zip code classified into quartiles did not 
appear to be strongly related to the type of device from which patients fall and sustain an injury. A slightly higher percentage of roller skaters $(29.2 \%)$ came from the lowest income quartile than patients who fell from bicycles, skateboards, or scooters. Roller skaters likewise tended to be somewhat underrepresented among patients from the most urbanized areas $(23.9 \%)$.

Not unexpectedly, visits to an ER were seasonally related. In general, patients who fell from each of the devices were more likely to visit an ER during the spring and summer months. One noteworthy finding, though, is that a fairly high percentage of roller skaters visited an ER during the months of January, February, and March (29.8\%). This finding could be attributed to the presence of indoor roller rinks which attract individuals during cooler months.

\subsection{Multivariate analysis: combining trends and demo- graphics}

Table 2 displays the results of the negative binomial regression analyses for each of the four types of devices. The table presents the exponentiated b's along with their $95 \%$ confidence intervals and their associated levels of statistical significance. Inspection of the table reveals that the trend lines for skateboards and scooters increased over time, but the trend line for roller skates decreased over time. No statistically significant trend line for bicycles was observable. These results depart somewhat from those obtained from the NEDS data in which a decrease in falling injuries from skateboards and bicycles was noted.

Table 2. Estimated Effects of Determinants on Injury-related Falls: Results of Negative Binomial Regression Analyses

\begin{tabular}{|c|c|c|c|c|}
\hline & $\begin{array}{l}\text { Bicycles } \\
\text { Exp (B);(95\%CI) }\end{array}$ & $\begin{array}{l}\text { Skateboards } \\
\text { Exp (B);(95\%CI) }\end{array}$ & $\begin{array}{l}\text { Roller skates } \\
\text { Exp (B);(95\%CI) }\end{array}$ & $\begin{array}{l}\text { Scooters } \\
\text { Exp (B);(95\%CI) }\end{array}$ \\
\hline Year & $1.02 ;(1.00,1.04)$ & $1.06^{* * *} ;(1.03,1.08)$ & $0.94^{* * *} ;(0.92,0.96)$ & $1.03^{* *} ;(1.01,1.06)$ \\
\hline \multicolumn{5}{|l|}{ Geographic region } \\
\hline New York State & $1.05 ;(0.88,1.26)$ & $0.97 ;(0.76,1.23)$ & $0.56^{* * *} ;(0.44,0.70)$ & $0.48^{* * *} ;(0.38,0.59)$ \\
\hline New York City & $0.63^{* * * *} ;(0.53,0.76)$ & $0.75^{*} ;(0.59,0.95)$ & $0.38^{* * *} ;(0.30,0.47)$ & $0.58^{* * *} ;(0.47,0.72)$ \\
\hline California & $1.32^{* *} ;(1.09,1.61)$ & $2.76^{* * *} ;(2.16,3.53)$ & $0.64^{* * *} ;(0.51,0.81)$ & $0.79^{*} ;(0.63,0.99)$ \\
\hline Los Angeles County & $0.77^{* *} ;(0.63,0.93)$ & $2.22^{* * *} ;(1.73,2.85)$ & $0.42^{* * *} ;(0.33,0.53)$ & $0.63^{* * *} ;(0.50,0.80)$ \\
\hline Maryland & $0.58^{* * *} ;(0.48,0.71)$ & $0.67^{* *} ;(0.52,0.86)$ & $0.45^{* * *} ;(0.35,0.57)$ & $0.39^{* * *} ;(0.31,0.49)$ \\
\hline Baltimore city & Ref. cat. & Ref. cat & Ref. cat. & Ref. cat. \\
\hline \multicolumn{5}{|l|}{ Gender } \\
\hline Male & $3.02^{* * * *} ;(2.75,3.30)$ & $4.20^{* * *} ;(3.79,4.66)$ & $0.67^{* * *} ;(0.60,0.74)$ & $1.85^{* * *} ;(1.67,2.04)$ \\
\hline Female & Ref. cat. & Ref. cat. & Ref. cat. & Ref. cat. \\
\hline \multicolumn{5}{|l|}{ Age category } \\
\hline Under 5 & $1.70^{* * *} ;(1.45,2.00)$ & $3.63^{* * *} ;(2.95,4.46)$ & $0.67^{* * *} ;(0.54,0.83)$ & $13.78^{* * *} ;(11.54,16.45)$ \\
\hline 5 to 9 & $5.39^{* * *} ;(4.60,6.30)$ & $25.23^{* * *} ;(20.87,30.50)$ & $9.59^{* * *} ;(8.08,11.39)$ & $47.09^{* * *} ;(39.61,55.98)$ \\
\hline 10 to 14 & $5.23^{* * *} ;(4.47,6.11)$ & $89.78^{* * *} ;(74.59,108.07)$ & $16.43^{* * *} ;(13.87,19.47)$ & $29.56^{* * *} ;(24.83,35.17)$ \\
\hline 15 to 24 & $2.45^{* * * *} ;(2.10,2.86)$ & $42.36^{* * *} ;(35.24,50.91)$ & $4.04^{* * *} ;(3.40,4.80)$ & $3.16^{* * *} ;(2.64,3.79)$ \\
\hline 25 to 44 & $1.48^{* * *} ;(1.27,1.73)$ & $6.46^{* * *} ;(5.36,7.78)$ & $2.64^{* * *} ;(2.23,3.12)$ & $1.35^{* *} ;(1.12,1.62)$ \\
\hline 45 and older & Ref. cat. & Ref. cat. & Ref. cat. & Ref. cat. \\
\hline \multicolumn{5}{|l|}{ Race/ethnicity } \\
\hline Non-Hispanic White & $1.57^{* * *} ;(1.38,1.78)$ & $1.84^{* * *} ;(1.60,2.11)$ & $2.23^{* * *} ;(1.94,2.56)$ & $1.44^{* *} ;(1.26,1.65)$ \\
\hline Non-Hispanic Black & $1.20^{* *} ;(1.06,1.36)$ & $1.21^{* *} ;(1.05,1.40)$ & $1.99^{* * *} ;(1.73,2.30)$ & $1.32^{* * *} ;(1.15,1.52)$ \\
\hline Non-Hispanic Asian & $0.45^{* * *} ;(0.40,0.52)$ & $0.37^{* * *} ;(0.32,0.43)$ & $0.53^{* * *} ;(0.45,0.62)$ & $0.46^{* * *} ;(0.40,0.54)$ \\
\hline Hispanic & Ref. cat. & Ref. cat. & Ref. cat. & Ref. cat. \\
\hline
\end{tabular}

Significance levels: ${ }^{* * *} p<.001 ;{ }^{* *} p<.01 ;{ }^{*} p<.05$

The table also shows considerable geographic variability in the likelihood of sustaining a fall from any one of the four wheeled devices. With a few exceptions, residents of Baltimore were more likely to sustain a fall than residents of the five other areas.

Consistent with the NEDS data discussed above, the table reveals that the odds of incurring a fall-related injury from bicycles, skateboards, and scooters were greater for males than females. Oppositely, the odds of incurring a fall-related injury from roller skates were less for males than females.

Coinciding with expectations, age played a prominent role in affecting the chances of an individual getting injured from 
a fall from each of the devices. Compared to patients 45 years of age and over, younger patients of all age ranges were considerably more likely to sustain an injury. This was particularly noticeable with respect to skateboards. The data revealed, for example, that patients in the 10 to 14 age bracket were almost 90 times more likely to be injured in a skateboard accident than patients 45 and older. Patients in the 15 to 24 age bracket were also markedly more likely to be injured in a fall from a skateboard than those in the highest age group by a ratio of 42.3 to 1 . Scooter riders offer another notable example of the effect of age on the incidence of fall-related injuries. Those in the 5 to 9 age bracket were 47 times more likely to sustain an injury than members of the reference group, and those in the 10 to 14 age bracket were 29.5 times more likely.

In addition to geographic location, gender, and age, racialethnic background also figured prominently in the odds of incurring a fall-related injury. For each of the four types of human-powered vehicles, non-Hispanic whites and nonHispanic blacks were more likely to incur an injury than Hispanics who comprise the reference group. What is particularly noteworthy is that non-Hispanic Asians were con- siderably less likely than the other three racial-ethnic groups to sustain an injury. Several reasons could be given for this finding ranging from different utilization patterns of the U.S. health care system, greater use of alternative medicine for treatment, or perhaps a tendency to be more risk-averse when using non-motorized vehicles. ${ }^{[23,24]}$

\subsection{Types of injury}

Table 3 presents the types of injuries based on the NEDS database for 2014. Overall, the two most common injury diagnoses were "fracture of upper limb" and "superficial injury" (tied at $20.6 \%$ each) followed in descending order by "sprains and strains" (12\%), "open wounds of head, neck, and trunk" (10.3\%), "open wounds of extremities" (5.3\%), and "intracranial injury" (5\%). Roller skaters were disproportionately found among those who suffered a fracture of an upper limb (32.5\%) as well as those who suffered a sprain or strain $(21.4 \%)$. Individuals who fell from scooters were overrepresented among those who suffered an open wound of the head, neck and trunk regions of the body (14.9\%). Individuals who fell from bicycles were overrepresented among those who sustained an open wound of the extremities (6.6\%).

Table 3. Types of Injuries to Patients Admitted to Emergency Departments: 2014

\begin{tabular}{llllll}
\hline Type of Injury & $\begin{array}{l}\text { Bicycles } \\
\mathbf{n}(\%)\end{array}$ & $\begin{array}{l}\text { Skateboards } \\
\mathbf{n}(\%)\end{array}$ & $\begin{array}{l}\text { Roller skates } \\
\mathbf{n}(\%)\end{array}$ & $\begin{array}{l}\text { Scooters } \\
\mathbf{n}(\%)\end{array}$ & $\begin{array}{l}\text { Total } \\
\mathbf{n}(\%)\end{array}$ \\
\hline \multirow{2}{*}{ Fracture of upper limb } & 52,203 & 19,693 & 10,782 & 7,977 & 90,655 \\
& $(17.5)$ & $(25.4)$ & $(32.5)$ & $(25.8)$ & $(20.6)$ \\
Superficial injury & 67,103 & 12,654 & 4,863 & 5,920 & 90,540 \\
& $(22.5)$ & $(16.3)$ & $(14.7)$ & $(19.2)$ & $(20.6)$ \\
Sprains and strains & 28,018 & 14,242 & 7,087 & 3,414 & 52,761 \\
Open wounds: head, & $(9.4)$ & $(18.4)$ & $(21.4)$ & $(11.1)$ & $(12.0)$ \\
neck, trunk & 34,283 & 5,307 & 1,124 & 4,598 & 45,312 \\
Open wounds: & $(11.5)$ & $(6.8)$ & $(3.4)$ & $(14.9)$ & $(10.3)$ \\
extremities & 19,586 & 2,231 & 260 & 1,437 & 23,514 \\
Intracranial injury & $(6.6)$ & $(2.9)$ & $(0.8)$ & $(4.7)$ & $(5.3)$ \\
& 15,759 & 4,171 & 837 & 1,054 & 21,821 \\
Fracture of lower limb & $(5.3)$ & $(5.4)$ & $(2.5)$ & $(3.4)$ & $(5.0)$ \\
& 9,475 & 5,163 & 2,689 & 1,352 & 18,679 \\
Other injuries & $(3.2)$ & $(6.7)$ & $(8.1)$ & $(4.4)$ & $(4.2)$ \\
& 71,923 & 14,104 & 5,518 & 5,128 & 96,673 \\
TOTAL & $(24.1)$ & $(18.2)$ & $(16.7)$ & $(16.6)$ & $(23.2)$ \\
\hline
\end{tabular}

To assess injury diagnoses among patients with more severe injuries, a subset of the 2014 NEDS database was created among those emergency room patients who were admitted to the same hospital, transferred to another hospital, or died in the emergency room. Table 4 displays the injury diagnoses assigned to this subset of patients by type of recreational vehicle. Heading the list of injury diagnoses now is "intracranial injury" (18.8\%), followed in descending order by "fracture of upper limb" (17.5\%), "fracture of lower limb" (13.3\%), "other fractures" (8.8\%), and "crushing or internal injury" and "fracture of hip" (both tied at $8.4 \%$ ). By a wide margin, skateboarders were disproportionately found 
among those who suffered an intracranial injury (29.4\%). (35.1\% and 31.2\%, respectively). Roller skaters also were Both scooter riders and roller skaters were overrepresented overrepresented among those diagnosed with a fracture of among those diagnosed with a fracture of the upper limb the lower limb (38.3\%).

Table 4. Types of Injuries to Patients Admitted to Hospital or Dying: 2014

\begin{tabular}{|c|c|c|c|c|c|}
\hline Type of injury & $\begin{array}{l}\text { Bicycles } \\
\text { n (\%) }\end{array}$ & $\begin{array}{l}\text { Skateboards } \\
\text { n (\%) }\end{array}$ & $\begin{array}{l}\text { Roller skates } \\
\text { n (\%) }\end{array}$ & $\begin{array}{l}\text { Scooters } \\
\text { n (\%) }\end{array}$ & $\begin{array}{l}\text { TOTAL } \\
\text { n (\%) }\end{array}$ \\
\hline Intracranial injury & $\begin{array}{l}4,163 \\
(18.3)\end{array}$ & $\begin{array}{l}1,089 \\
(29.4)\end{array}$ & $\begin{array}{l}76 \\
(6.0)\end{array}$ & $\begin{array}{l}79 \\
(8.0)\end{array}$ & $\begin{array}{l}5,407 \\
(18.8)\end{array}$ \\
\hline $\begin{array}{l}\text { Fracture of upper } \\
\text { limb }\end{array}$ & $\begin{array}{l}3,459 \\
(15.2)\end{array}$ & $\begin{array}{l}834 \\
(22.5)\end{array}$ & $\begin{array}{l}393 \\
(31.2)\end{array}$ & $\begin{array}{l}346 \\
(35.1)\end{array}$ & $\begin{array}{l}5,032 \\
(17.5)\end{array}$ \\
\hline $\begin{array}{l}\text { Fracture of lower } \\
\text { limb }\end{array}$ & $\begin{array}{l}2,289 \\
(10.1)\end{array}$ & $\begin{array}{l}832 \\
(22.4)\end{array}$ & $\begin{array}{l}482 \\
(38.3)\end{array}$ & $\begin{array}{l}220 \\
(22.2)\end{array}$ & $\begin{array}{l}3,823 \\
(13.3)\end{array}$ \\
\hline Other Fractures & $\begin{array}{l}2,408 \\
(10.6)\end{array}$ & $\begin{array}{l}53 \\
(1.4)\end{array}$ & $\begin{array}{l}54 \\
(4.3)\end{array}$ & $\begin{array}{l}22 \\
(2.2)\end{array}$ & $\begin{array}{l}2,537 \\
(8.8)\end{array}$ \\
\hline $\begin{array}{l}\text { Crushing or } \\
\text { internal injury }\end{array}$ & $\begin{array}{l}2,239 \\
(9.8)\end{array}$ & $\begin{array}{l}107 \\
(2.9)\end{array}$ & $\begin{array}{l}17 \\
(1.3)\end{array}$ & $\begin{array}{l}39 \\
(4.0)\end{array}$ & $\begin{array}{l}2,402 \\
(8.4)\end{array}$ \\
\hline Fracture of hip & $\begin{array}{l}2,091 \\
(9.2)\end{array}$ & $\begin{array}{l}129 \\
(3.5)\end{array}$ & $\begin{array}{l}121 \\
(9.6)\end{array}$ & $\begin{array}{l}56 \\
(5.7)\end{array}$ & $\begin{array}{l}2,397 \\
(8.4)\end{array}$ \\
\hline $\begin{array}{l}\text { Skull and face } \\
\text { fractures }\end{array}$ & $\begin{array}{l}1,549 \\
(6.8)\end{array}$ & $\begin{array}{l}229 \\
(6.2)\end{array}$ & $\begin{array}{l}11 \\
(0.9)\end{array}$ & $\begin{array}{l}60 \\
(6.1)\end{array}$ & $\begin{array}{l}1,849 \\
(6.4)\end{array}$ \\
\hline Other injuries & $\begin{array}{l}4,543 \\
(20.0)\end{array}$ & $\begin{array}{l}436 \\
(11.8)\end{array}$ & $\begin{array}{l}106 \\
(16.7)\end{array}$ & $\begin{array}{l}166 \\
(16.8)\end{array}$ & $\begin{array}{l}5,251 \\
(18.3)\end{array}$ \\
\hline TOTAL & $\begin{array}{l}22,741 \\
(100.0)\end{array}$ & $\begin{array}{l}3,709 \\
(100.0)\end{array}$ & $\begin{array}{l}1,260 \\
(100.0)\end{array}$ & $\begin{array}{l}988 \\
(100.0)\end{array}$ & $\begin{array}{l}28,698 \\
(100.0)\end{array}$ \\
\hline
\end{tabular}

\section{Discussion}

This study has found that the incidence of falling injuries from bicycles far exceeds the incidence of falls from skateboards, roller skates, or non-motorized scooters. Unquestionably, a major reason for the relatively high rate of injuries incurred by falls from a bicycle is the popularity of bicycle riding spanning all age groups. While users of skateboards, roller skates, and scooters tend to skew to relatively younger age groups (e.g., children and adolescents), bicycle use is more evenly distributed by age, with a considerable portion of bicycle riders in their adult and senior years. ${ }^{[19,20]}$ Not only are bicycle riders more uniformly distributed across age groups, but the sheer number of bicycle riders vastly exceeds riders of the other three vehicles, either separately or combined (ibid.). Unlike skateboarding, roller-skating, or scootering, which tend to be confined to children and adolescents, bicycle riding appeals to young and old alike. Public health officials need to be mindful that while certain wheeled activities such as scootering might be on the rise, nevertheless, the number of injuries sustained from bicycle falls still dwarfs the number of injuries owing to falls from skateboards, roller skates, and scooters combined. Thus special attention needs to be paid to both prevent injury-related falls from bicycles and specific treatment modalities.

This study has also documented considerable geographic variation in the rate of fall-related injuries by type of nonmotorized vehicle. With respect to bicycles, for example, the incidence of injury-related falls in California is 130 per 100,000 inhabitants while the comparable figure for New York is just about half that rate at 66.83 per 100,000 inhabitants. Similarly, regarding skateboards, in California the rate is 52 whereas in New York, the rate is a scant 18.92. It is important for public health officials in states and municipalities to gather data on the magnitude of injury rates by type of vehicle in their localities in order to allocate prevention and treatment resources more efficiently.

As might be expected, wide disparities exist in the demographic characteristics of patients who incur an injury from a fall from one of the four human-powered vehicles investigated in this study. In terms of age group, while patients who fall from a bicycle tend to be fairly evenly distributed across all age groups, nearly half $(47.2 \%)$ of patients who fall from a skateboard are concentrated in the 15 to 24 age group and more than two fifths $(41.8 \%)$ of patients who fall from a non-motorized scooter are concentrated in the 5 to 9 age group. With respect to gender, males are lopsidedly more likely to sustain an injury-related fall from each of the devices with the exception of roller skates where females predominate among patients. 
The multivariate analysis conducted in this study also points to the importance of the racial-ethnic background of patients in terms of their likelihood of sustaining an injury from a fall. What is noteworthy is that non-Hispanic Asians are markedly less likely to become an ER patient due to an injury-related fall than non-Hispanic whites, non-Hispanic blacks, or Hispanics. This finding persists across each of the four human-powered devices. Several explanations have been offered in the literature which may account for the underrepresentation of Asians in emergency room departments. These include barriers to utilizing health care facilities in general (e.g., language, cultural inhibitions, lack of health insurance, etc.), ${ }^{[23,24]}$ diet, use of alternative medicine, and culturally-based patterns of behavior which discourage risk taking. This topic needs to be investigated further to determine whether Asians, in fact, are less likely to sustain a fall-related injury from a wheeled device or are just as likely as other racial groups but for any number of the aforementioned reasons have a reduced presence in an emergency room. If it can be determined that Asians are just as likely as other racial groups to have a falling injury, then it would be important to sort out the causative explanations accounting for their relative absence from emergency rooms.

Seasonal patterns in injuries from falls generally conform to expectations. Most patients arrive at an emergency department either in the spring or summer months. One notable exception, however, is the disproportionately large number of individuals who fall from roller skates $(29.8 \%)$ who visit an ER room in the months of January, February, and March. This finding may be due to roller skating at indoor rinks which are popular among young people in the winter months.

Lastly, this study examined injury diagnoses assigned to patients who fell from bicycles, skateboards, roller skates, and scooters. Overall, "fracture of upper limb", "superficial injury", "sprains and strains" and "open wounds of head, neck, trunk" were the most prevalent diagnoses among outpatients. Among patients who were severely injured and who either were admitted as inpatients to a hospital or died in the emergency room, "intracranial injury", "fracture of the upper limb", "fracture of the lower limb", "other fractures", or "crushing or internal injury" were the most common types of diagnoses. These findings underscore the need for repeated exhortations by public health practitioners that users of non-motorized devices should wear protective gear such as helmets, and elbow, knee and wrist pads. Studies have consistently found that the use of protective gear greatly reduces the chances of fall-related injuries from wheeled devices. ${ }^{[25-27]}$ Adding to this imperative is the continuing rise in the costs of treating patients who have suffered a fall-related injury.

\section{Limitations}

This study rests on data extracted from outpatient and inpatient hospital records of individuals who have fallen from a bicycle, skateboard, roller skates, or non-motorized scooter. One limitation which is attached to this study is that estimates of both the incidence of injuries and the characteristics of individuals who suffer an injury are based on patient populations and not based on the overall populations of users of these devices. Thus the findings uncovered in this study could reflect varying levels of participation in cycling, skateboarding, roller-skating, or scootering on the part of distinct patient subgroups and not only the propensity to incur an injury. Unfortunately, as noted above, only a paucity of information exists concerning levels of participation in each of the activities. Public health officials should consider expending greater efforts gathering data about the "exposure" of individuals who sustain different types of injuries. Information should be collected about the "relative risk" of different subgroups in the population that incur injuries from recreational activities rather than just relying on their proportionate representation in the population.

In addition to not knowing the "risk of exposure" (i.e., levels of participation of patient subgroups in these four wheeled activities), a second limitation of this study is that most of the data reported on here rely on emergency room visits. While individuals who suffer a fall-related injury from a wheeled device have always had alternative venues in which to seek treatment (e.g., their private physician), the choice of venues is now rapidly expanding. One reason for this is the expansion in the number of urgent care centers which are competing more than ever before with emergency room departments as treatment centers. ${ }^{[28]}$ As a result, patients who visit emergency rooms represent an increasingly smaller share of patients in general and thereby restrict the generalizability of the findings from ER visits.

Despite these limitations, it is likely that a broad swath of individuals who suffer an injury of the type discussed in this study visit an ER. It is important to continue to describe the characteristics of ER patients and to monitor changes in their characteristics over time.

\section{Conclusions}

Falls from bicycles, skateboards, roller skates and nonmotorized scooters lead to a substantial number of injuries in the United States. The associated emergency department charges are sizeable and have been growing. A significant segment of the injuries sustained by the victims are quite serious, and in many cases serious enough to lead to a hospital admission. There are marked differences in the incidence of injuries among the four types of devices with falls 
from bicycles being the leading cause of injury. There is also considerable geographic variability in the incidence of fall-related injuries as well as variability among different demographic subgroups. Public health officials need to be aware of the extent and nature of these injuries. Campaigns to promote safe use of these devices and the use of protective gear could reduce the number and severity of injuries.

\section{CONFlicts OF INTEREST Disclosure}

The authors declare that they have no competing interests.

\section{REFERENCES}

[1] Nationwide Emergency Department Sample (NEDS). Data from 2014. Healthcare Cost and Utilization Project (HCUP), Agency for Healthcare Research and Quality. [cited 2017 May 11]. Available from: https://www.distributor .hcup-us .ahrq.gov/

[2] Chen WS, Dunn RY, Chen AJ, et al. Epidemiology of nonfatal bicycle injuries presenting to United States emergency departments, 2001-2008. Academic Emergency Medicine. 2013; 20(6): 570-5. PMid:23758303 https://doi.org/10.1111/acem.12146

[3] McKenzie LB, Fletcher E, Nelson NG, et al. Epidemiology of skateboarding-related injuries sustained by children and adolescents 5-19 years of age and treated in US emergency departments: 1990 through 2008, Injury Epidemiology. 2016; 3(1): published online 8 April 2016.

[4] Shuman KM, Meyers MC. Skateboarding injuries: an updated review. The Physician and Sportsmedicine. 2015; 43(3): 317 23. PMid:26018674 https : //doi .org/10.1080/00913847.201 5.1050953

[5] Committee on Injury and Poison Prevention and Committee on Sports Medicine and Fitness. In-line skating injuries in children and adolescents. Pediatrics. 1998; 101(4): 720-2. https://doi.org/10.154 2/peds.101.4.720

[6] Haze N. Scootermania: implications for pediatric nurses. Pediatric Nursing. 2001; 27(3):272-5. PMid:12964666

[7] Josefson D. Scooters cause 9,500 injuries in US in 8 months. The Western Journal of Medicine. 2000; 173(5):297-8. https://doi . org/10.1136/ewjm.173.5.297-a

[8] Powell EC, Tanz RR. Incidence and description of scooter-related injuries among children. Ambulatory Pediatrics. 2004; 4(6):495-9. PMid:15548100 https://doi.org/10.1367/A04-074R1.1

[9] Abraham VM, Gaw CE, Chounthirath T, et al. Toy-related injuries among children treated in US emergency departments, 1990-2011. Clinical Pediatrics. 2015; 54(2):127-37. PMid:25452624 https: //doi.org/10.1177/0009922814561353

[10] Baker SP, Fowler C, Warner M, et al. Head injuries incurred by children and young adults during informal recreation. American Journal of Public Health. 1994; 84(4):649-52. https : //doi .org/10. 210 5/AJPH. 84. .4.649

[11] Kaddis M, Stockton K, Kimble R. Trauma in children due to wheeled recreational devices. Journal of Paediatric and Child Health 2016; 52(1):30-3. PMid:26302989 https://doi.org/10.1111/ jpc.12986

[12] Lindsay H, Brussoni M. Injuries and helmet use related to nonmotorized wheeled activities among pediatric patients. Chronic Diseases and Injuries in Canada. 2014; 34(2-3):74-81. PMid:24991770

[13] Nathanson BH, Ribeiro K, Henneman P. An analysis of US emergency department visits from falls from skiing, snowboarding, skateboarding, roller-skating, and using non-motorized scooters. Clinical Pediatrics. 2015; 55(8):738-44. PMid:26324666 https : //doi .or g/10.1177/0009922815603676

[14] Nationwide Emergency Department Sample (NEDS). Data from 2006, 2009, 2012 and 2014. Healthcare Cost and Utilization Project (HCUP), Agency for Healthcare Research and Quality. [cited 2017
May 11]. Available from: https://www.distributor.hcup-us . ahrq.gov/

[15] Nationwide Inpatient Sample (NIS). Inpatient and outpatient data from 2006, 2009, 2012 and 2014. Healthcare Cost and Utilization Project (HCUP), Agency for Healthcare Research and Quality. [cited 2017 May 11]. Available from: https://www.distributor.hc up-us.ahrq.gov/

[16] Statewide Planning and Research Cooperative System (SPARCS). Data from 2005 to 2014. New York State Department of Health. [cited 2017 May 15]. Available from: https://www.health.ny. gov/statistics/sparcs/access/

[17] California Office of Statewide Health Planning and Development. Patient discharge data, emergency department data and ambulatory surgery data from 2009 to 2014. [cited 2017 May 17]. Available from: https://www.oshpd.ca.gov/HID/\#Find

[18] State Inpatient Databases (SID), State Emergency Department Databases (SEDD) and State Ambulatory Surgery and Services Databases (SASD) for Maryland. Data from 2009 to 2014. Healthcare Cost and Utilization Project (HCUP), Agency for Healthcare Research and Quality. [cited 2017 May 18]. Available from: https ://www .hcup-us . ahrq.gov/databases.jsp

[19] Sports \& Fitness Industry Association. Bicycling (Road/Paved Surface) Single Sport Participation Report. 2016.

[20] Sports \& Fitness Industry Association. Bicycling (BMX) Single Sport Participation Report. 2016.

[21] Sports \& Fitness Industry Association. Skateboarding Single Sport Participation Report. 2016

[22] Sports \& Fitness Industry Association. Roller Skating Single Sport Participation Report. 2016

[23] Yu SM, Huang ZJ, Singh GK. Health status and health services utilization among US Chinese, Asian, Indian, Filipino, and Other Asian/Pacific Islander children. Pediatrics. 2004; 113(1):101-7. https://doi.org/10.1542/peds.113.1.101

[24] Zook H. Emergency department use by Asian-American children. Unpublished masters thesis. University of Minnesota. 2015

[25] American Academy of Pediatrics, Committee on Injury and Poison Prevention. Bicycle Helmets. Pediatrics. 2001; 108(4):1030-2. PMid:11581464

[26] Lustenberger T, Talving P, Barmparas G, et al. Skateboard-related injuries: not to be taken lightly. The Journal of Trauma and Acute Care Surgery. 2010; 69(4):924-7. PMid:20065875 https://doi. org/10.1097/TA.0b013e3181b9a05a

[27] Page JL, Macpherson AK, Middaugh-Bonney T, et al. Prevalence of helmet use by users of bicycles, push scooters, inline skates and skateboards in Toronto and the surrounding area in the absence of comprehensive legislation: an observational study. Injury Prevention. 2012; 18(2):94-7. PMid:21873306 https://doi.org/10.1136/ injuryprev-2011-040029

[28] Urgent Care Association of America. UCAOA 2016 Benchmarking Report Shows Wait Times of 30 Minutes or Less at 92 Percent of Centers. 2017. http://www. prweb. com/releases/2017/01/p rweb13987046.htm Accessed on June 2, 2017. 